\title{
Distress, depression and coping in HLA-B27-associated anterior uveitis with focus on gender differences
}

\author{
S M Maca, ${ }^{1}$ A W Schiesser, ${ }^{2}$ A Sobala, ${ }^{1}$ K Gruber, ${ }^{3}$ G Pakesch, ${ }^{4}$ C Prause, ${ }^{5}$ \\ T Barisani-Asenbauer $^{1}$
}

${ }^{1}$ Department of Ophthalmology, Medical University Vienna, Vienna, Austria 2Department of Psychology, Sigmund Freud University, Vienna, Austria

${ }^{3}$ Hogrefe Verlag, Vienna, Austria ${ }^{4}$ Department of Psychiatry. Medical University Vienna, Vienna, Austria

${ }^{5}$ Department of Pediatric Psychiatry, Medical University Vienna, Vienna, Austria

\section{Correspondence to}

Professor Talin

Barisani-Asenbauer, Laura Bassi

Centre for Expertise Ocuvac,

Centre for Pathophysiology,

Immunology \& Infectiology,

Medical University of Vienna,

Kinderspitalgasse 15, 1090

Wien Austria;

ocuvac@meduniwien.ac.at

Dr S M Maca is currently working at the Hietzing Hospital, Vienna, Austria.

Accepted 18 July 2010

Published Online First

22 October 2010

\section{ABSTRACT}

Background/aims To evaluate depression, coping with disease and stress, and the subjective impression of distress and/or life events as triggers for recurrences in HLA-B27-associated anterior uveitis (B27-AU), with attention to gender-specific characteristics.

Methods 171 patients with a history of B27-AU responded to a postal survey performed between January 2006 and April 2008 using standardised psychological questionnaires: Beck Depression Inventory, Freiburg Questionnaire on Coping with IIIness, and Stress Coping Inventory.

Results Patients with B27-AU differed from healthy controls showing more depressive symptoms (Beck Depression Inventory, 31.6\%), applying characteristic disease coping as well as negative stress coping strategies. Female B27-AU patients tended to react with depression and male patients to use negative stress coping strategies. $57.9 \%$ of patients believed that psychological distress was a trigger for relapses, and $34.5 \%$ stated specific life events. Together, this group of patients achieved higher depression scores and used more negative disease and stress coping styles than patients without perception of distress.

Conclusion Patients with B27-AU patients exhibited significant psychopathology concerning depression and disease coping. Distress and life events were subjectively suspected to be a trigger. By imparting knowledge to the patients on probable development of depressive moods and the role of stress/life events as trigger for relapses, as well as offering behaviour therapy to optimise coping, may help patients to cope better with B27-AU.

Uveitis associated with the HLA-B27 antigen (B27-AU) is an acute-onset, painful eye disease with a relapse risk of up to $74 \%{ }^{1}$ The treatment consists of anti-inflammatory topical and systemic therapy as well as pharmacologic cycloplegia for reduction of pain and prevention of synechiae. At each recurrence the pain, as well as the deterioration of visual acuity due to inflammation and impaired accommodation pose a strain for the patients. Furthermore, they may require sick leave for several days, lose their ability to perform certain tasks (ie, reading, working on a computer, driving), and face a risk of losing their jobs. The fact that a patient with a history of B27-AU is at permanent risk for a relapse of disease, associated with pain and fear of a transient or even persistent loss of vision, causes omnipresent distress (negative forms of stress, compared with positive forms of stress (eustress)) and poses a chronic psychological burden. For rheumatic diseases in general, as well as for ankylosing spondylitis in particular, a higher prevalence of depression has been reported. ${ }^{2}{ }^{3}$ In a pilot study, Franke et al dealt with the psychopathology of patients with various forms of uveitis and pointed out the importance of evaluating psychological interventions for rehabilitation. ${ }^{4}$

However, distress does not only play a role as a consequence of disease. Psychological stress also has been discussed as a probable trigger for uveitis, as patients often report the onset of relapses during or after periods of increased psychological pressure causing a negative mood. Specific life events can cause such distress and therefore have been investigated in this context. So far, clinical studies on uveitis have yielded disparate results. ${ }^{4-14}$ For other auto-immune diseases, such as multiple sclerosis or Behcet's disease, stressful life events were shown to represent an aggravating factor, as they resulted in a significant increase in risk of disease exacerbations. ${ }^{15} 16$

The aim of the present study was to evaluate the role of distress as a trigger from the patients' point of view, as well as to objectively evaluate the presence of depressive moods and the strategies used to cope with disease and stress. We decided to include only patients with a history of anterior uveitis associated with the HLA-B27-antigen, to obtain a large and homogenous patient population. A further point of interest was to delineate genderspecific differences. The results could help to gain further insight into the psychopathology of B27-AU and underline the importance of psychological interventions.

\section{MATERIALS AND METHODS \\ Patient recruitment}

This clinic-based, cross-sectional study was performed at the Uveitis Unit of the Department of Ophthalmology, Medical University of Vienna, from January 2006 to April 2008. A written invitation to participate in the study via a postal survey was sent once to 381 B27-AU patients who had been treated at the Uveitis Unit since 1980. A total of 171 patients (45\%) with recent and/or recurrent history of acute B27-AU responded with a completed questionnaire and were included in the study. Patients had to indicate whether an acute relapse was present or not. The booklet containing the questionnaire was prefaced by a general invitation letter explaining the scientific character of 
the survey and that the participation was voluntary. Patients were informed that the impact of stress on disease coping in patients with $\mathrm{AU}$ was being studied, and the expressions 'gender', 'depression' and 'trigger' were not used. Normative values were obtained in an ethnicity- and aged-matched control group of 55 healthy individuals (mean age 45.6 \pm 10.1 years, $\mathrm{p}=0.1)$

The survey consisted of three psychometric instruments, listed below, as well as questions related to sociodemographic data (gender, age) and uveitis details (age at onset of uveitis, the number of recurrences in total and approximately per year, the approximate duration of attacks and interval since the last recurrence, coexistence of a B27-associated spondylarthropathy). Furthermore, patients were questioned on the presence of psychological factors before an attack. Patients could indicate specific live events that subjectively were suspected to be connected with a relapse.

\section{Psychometric instruments}

The Beck Depression Inventory (BDI) is a self-report inventory for differentiation of a clinically relevant depressive mood. ${ }^{17}$ Twenty questions document the actual severity of depressive moods, indicated by a sum score ( $0-63$ points). The sum score also is allocated to one of three clinically relevant groups: 'not depressed' (0-9 points), 'minimal depressive mood' (9 to 19 points), and 'clinical relevant depressive mood' (19-63 points).

Coping was assessed by the Freiburg Questionnaire on Coping with Illness (FOCI). ${ }^{18}$ This 35 -item questionnaire is used to calculate five primary dimensions (subscales): 'depressive coping', 'problem-solving behaviour','distraction and self-revalorisation' (encouraging oneself), 'religiousness/quest for meaning' (each 5-25 points) and 'cognitive avoidance/ dissimulation' (trivialising and wishful thinking, 3-15 points). A high score in a FOCI subscale indicates a strong tendency to apply this type of coping mechanism.

Coping was also assessed by the Stress Coping Inventory (SCI) questionnaire, which consists of 114 items. ${ }^{19}$ Item scores (each $0-4$ points) are grouped to calculate 19 subscales that describe various coping strategies (combination of six item scores, $0-24$ points). Alternatively, the items may also be classified into two secondary dimensions, namely 'negative' or 'positive coping' strategies (0-24 points).

\section{Statistics}

The SPSS 16.0 software was used for statistical analysis. For descriptive analysis, data are expressed as total numbers (n), percentage relating to group (\%) and means \pm SD. The Kolmogorov-Smirnoff test was used to test for standard distribution, the $t$ test or Mann-Whitney $U$ test was used as appropriate. The cut-off level for statistical significance was set at $\mathrm{p}<0.05$; all tests were performed in a two-tailed manner. In case of multiple testing within a group (gender comparisons concerning BDI items, FQCI and SCI), a Bonferroni-Holm correction for adjustment of the $p$ value was applied. ${ }^{20}$

\section{RESULTS}

A total of 171 patients with known B27-AU, 64 women and 107 men, returned the questionnaires. The gender distribution was female:male 1:1.7 ( $p<0.001$, table 1$)$.

Thirteen patients $(7.6 \%)$ had active recurrence at the time of answering the questionnaire; there was a B27-associated spondylarthropathy in 75 patients (43.9\%). Altogether, the patients had suffered from approximately $12.9 \pm 20.1$ uveitis relapses since disease onset, which had been $14.3 \pm 9.6$ years ago. More
Table 1 Patient characteristics for sociodemographics and history of HLA-B27-associated anterior uveitis (B27-AU)

\begin{tabular}{|c|c|c|c|}
\hline & $\begin{array}{l}\text { Total patient } \\
\text { population }\end{array}$ & Women & Men \\
\hline Number of patients (n (\%)) & 171 & $64(37.4)$ & $107(62.6) \dagger$ \\
\hline Current age (years $\pm S D$ ) & $48.8(14.1)$ & $46.6(14.9)$ & $50.2(13.4)$ \\
\hline Age at onset of uveitis (years $\pm S D$ ) & $34.5(12.6)$ & $33.0(11.4)$ & $35.5(13.3)$ \\
\hline \multicolumn{4}{|l|}{ Uveitis relapses* } \\
\hline Total numbers $(\mathrm{n} \pm \mathrm{SD})$ & $12.9(20.1)$ & $12.6(18.6)$ & $13.2(21.0)$ \\
\hline Approximate relapses per year $(n \pm S D)$ & $2.5(1.9)$ & $2.9(1.9)$ & $2.3(1.9)$ \\
\hline Duration (weeks \pm SD) & $4.9(4.1)$ & $5.5(5.0)$ & $4.6(3.4)$ \\
\hline $\begin{array}{l}\text { Acute B27-AU at time of study } \\
\text { participation }(\mathrm{n}(\%))\end{array}$ & $13(7.6)$ & $5(7.8)$ & $8(7.5)$ \\
\hline $\begin{array}{l}\text { HLA-B27-associated spondylarthropathy } \\
\text { (n (\%)) }\end{array}$ & $78(45.6)$ & $27(42.2)$ & $51(47.7)$ \\
\hline
\end{tabular}

Data are given as total numbers or means; SD or percentage relating to groups is given in parentheses.

${ }^{*}$ As subjectively reported by patients.

†Significance at $\mathrm{p}<0.05$.

information concerning uveitis recurrences is given in table 1. No differences in sociodemographic data were found comparing patients who responded to the survey with those who did not.

\section{BDI}

The mean total score obtained in patients with B27-AU was significantly higher than the value obtained from the control group ( $8.7 \pm 7.0$ and $4.4 \pm 4.3$, respectively, $p<0.001$, table 2 , figure 1). Patients with an acute relapse scored even worse (11.3 $\pm 7.7, p=0.19)$, the coexistence of an additional spondylarthropathy did not affect the score (9.5 $\pm 7.6, p=0.13)$. Among the $\mathrm{B} 27-\mathrm{AU}$ patients, $31.6 \%(\mathrm{n}=54)$ were above 'normal range', as $19.3 \%$ were classified to be in a 'minimal depressive' and $12.3 \%$ in a 'clinical relevant depressive' mood.

Thirty-six per cent of women and $28.9 \%$ of men exhibited depressive moods $(p=0.34)$, the mean total sum score was slightly higher in the female group (table 2). In female and male B27-AU patients the scores were significantly higher than those of the corresponding healthy comparison groups (table 2 , figure 1). For the individual test items women suffered more

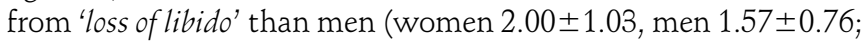
$\mathrm{p}=0.002$ ).

\section{FQCI}

B27-AU patients exhibited different patterns from controls for three of five coping styles. Both women and men tended towards 'cognitive avoidance and dissimulation' ( $p<0.001$, table 2). Women in particular seemed to lose the ability for 'distraction and self-revalorisation' $(\mathrm{p}=0.030)$, whereas men tended to apply a 'problem-solving behaviour' $(\mathrm{p}=0.004)$.

\section{German stress coping inventory}

Compared with healthy controls, B27-AU patients reached higher scores on four of 19 subscales, leading to a statistically significant increase of the secondary dimension negative coping (table 2, $\mathrm{p}=0.005$ ). Splitting these findings according to gender, female patients seemed to 'play down the disease' less $(p=0.030)$, needed more 'social support' (mean score was significantly higher than in B27-AU males although it should have been similar), used less 'self-medication' $(p=0.005)$, but reacted with more 'rumination' ( $\mathrm{p}=0.020)$ than healthy controls. Male patients also tended to use 'rumination' ( $\mathrm{p}=0.003$ ), but in addition exhibited aggravated patterns in eight more subscales, displayed in table 2. Summarised, these patterns are reflected in an elevated score of 'negative coping' in men $(\mathrm{p}=0.002)$. 
Table 2 Results of statistical significance as obtained by the Beck Depression Inventory (BDI), Freiburg Questionnaire of Coping with Illness (FOCI) and Stress Coping Inventory (SCI) in patients with HLA-B27associated anterior uveitis (B27-AU) and an age-matched, healthy control group

\begin{tabular}{llllll}
\hline & Patients (P) & & & & $\begin{array}{l}\text { p Value } \\
\text { for gender } \\
\text { differences }\end{array}$ \\
\hline Numbers & vs controls (C) & Total & Women & Men & $\begin{array}{l}\text { donch } \\
\text { BDI sum score }\end{array}$ \\
& $\mathrm{P}$ & 171 & 64 & 107 & \\
& $\mathrm{P}$ & 55 & 33 & 22 & \\
& $\mathrm{C}$ & $8.7(7.0)$ & $9.5(7.6)$ & $8.4(6.7)$ & n.s. \\
& & $4.4(4.3)$ & $4.5(4.0)$ & $4.1(4.7)$ & n.s. \\
& & $\mathrm{p}<0.001^{*}$ & $\mathrm{p}=0.004^{*}$ & $\mathrm{p}=0.02^{*}$ &
\end{tabular}

FOCI

Problem-solving $\mathrm{P}$

behaviour C

Distraction and $P$

self-revalorisation $\mathrm{C}$

Cognitive P

avoidance and

dissimulation

SCl

Playing down $P$

the disease $\quad \mathrm{C}$

Substitutional $P$

satisfaction C

Attempt to $P$

control reactions $\mathrm{C}$

Need for social $P$

support $\quad$ C

Avoidance $\quad P$

tendency C

Flight tendency $\mathrm{P}$

C

Social

withdrawal

Rumination/ P

pensiveness $\mathrm{C}$

Resignation $\mathrm{P}$

C

Self-pity P

C

Self-accusation $\quad P$

C

Aggression $\quad \mathrm{P}$

C

Use of self- $\quad P$

medication $\mathrm{C}$
16.2 (4.7) 16.5 (5.2) 16.1 (4.4) n.s. 14.1 (3.7) 14.9 (2.9) 13.0 (4.4) n.s. $\mathrm{p}=0.004^{*}$ n.s. $\quad \mathrm{p}=0.004^{*}$ 15.2 (4.2) 15.7 (4.4) 14.9 (4.0) n.s. 16.7 (3.7) $17.6(3.1) \quad 15.5$ (4.3) n.s. n.s. $\quad \mathrm{p}=0.030^{*}$ n.s.

$6.6(2.8) \quad 7.0(3.1) \quad 6.4(2.6) \quad$ n.s.

$4.5(1.9) \quad 4.3(1.5) \quad 4.7(2.4) \quad$ n.s. $p<0.001 * p<0.001 * p=0.005^{*}$

10.6 (4.7) $9.4(4.6) \quad 11.3$ (4.7) $\quad$ n.s. 12.3 (4.3) $10.7(4.2) \quad 13.0$ (4.6) n.s. $\mathrm{p}=0.02^{*} \quad \mathrm{p}=0.030^{*}$ n.s.

10.2 (5.7) $12.0(5.2) \quad 9.0(5.7) \quad \mathrm{p}=0.002 \dagger$

11.0 (4.4) 12.4 (4.3) 9.4 (4.1) $\quad \mathrm{p}<0.001 \dagger$

n.s. n.s. n.s.

14.6 (4.4) 14.3 (4.5) 14.8 (4.3) n.s.

13.4 (3.8) 14.4 (3.4) 13.0 (4.7) n.s.

n.s. n.s. $\quad \mathrm{p}=0.02^{*}$

12.9 (5.6) $15.4(5.3) \quad 11.3(5.2) \quad \mathrm{p}<0.001 \dagger$

13.5 (5.7) 14.9 (5.3) 12.7 (5.3) n.s.

n.s. n.s. n.s.

13.5 (5.1) 14.4 (4.7) 12.9 (5.3) n.s.

$11.3(5.3) \quad 12.8(5.3) \quad 9.9(5.0) \quad$ n.s.

$\mathrm{p}=0.008^{*}$ n.s. $\quad \mathrm{p}=0.010^{*}$

10.6 (4.7) $11.4(4.8) \quad 10.1$ (4.6) n.s.

$9.4(4.2) \quad 10.8(4.6) \quad 8.4(3.6) \quad \mathrm{p}=0.001 \dagger$

n.s. n.s. $\quad p=0.006^{*}$

$7.6(5.3) \quad 7.8(5.1) \quad 7.4(5.4) \quad$ n.s.

$5.5(4.3) \quad 6.5(4.3) \quad 5.4(4.7) \quad$ n.s.

$\mathrm{p}=0.009$ * n.s. $\quad \mathrm{p}=0.009^{*}$

15.0 (5.7) 16.4 (5.1) 14.1 (5.9) n.s.

$12.0(5.5) \quad 13.7(5.8) \quad 10.0(5.1) \quad$ n.s.

$\mathrm{p}=0.002^{*} \mathrm{p}=0.020^{*} \mathrm{p}=0.003^{*}$

$7.3(5.2) \quad 8.3(5.3) \quad 6.6(5.1) \quad$ n.s.

$5.7(4.6) \quad 7.3(5.0) \quad 4.6(3.3) \quad$ n.s.

n.s. n.s. $\quad p=0.010^{*}$

$8.9(5.6) \quad 10.1(5.8) \quad 8.2(5.4) \quad$ n.s.

$7.6(4.7) \quad 9.1(4.8) \quad 6.5(4.0) \quad$ n.s.

n.s. n.s. $\quad \mathrm{p}=0.063^{*}$

$9.0(4.8) \quad 9.6(5.6) \quad 8.6(4.3) \quad$ n.s

$7.7(4.4) \quad 9.0(4.5) \quad 6.8(4.7) \quad$ n.s

n.s n.s $\quad \mathrm{p}=0.016^{*}$

$8.8(5.5) \quad 8.6(4.9) \quad 9.0(5.9) \quad$ n.s

$7.9(4.7) \quad 8.8(4.4) \quad 7.0(4.6) \quad n . s$

n.s $\quad$.s $\quad \mathrm{p}=0.084^{*}$

$2.2(3.3) \quad 2.0(2.5) \quad 2.3(3.7) \quad$ n.s

$2.9(3.9) \quad 3.7(4.2) \quad 3.2(3.9) \quad$ n.s

n.s $\quad \mathrm{p}=0.005^{*}$ n.s
Table 2 Continued

\begin{tabular}{llllll}
\hline & Patients (P) & & & & $\begin{array}{l}\text { p Value } \\
\text { for gender } \\
\text { vs controls (C) }\end{array}$ \\
& Total & Women & Men & $\begin{array}{l}\text { differences } \\
\text { Negative coping }\end{array}$ \\
style & $\mathrm{C}$ & $9.7(4.2)$ & $10.6(4.2)$ & $9.1(4.1)$ & $\mathrm{p}=0.027^{\dagger}$ \\
& & $7.9(3.9)$ & $9.3(4.0)$ & $7.3(3.5)$ & $\mathrm{p}=0.008^{\dagger}$ \\
& $\mathrm{p}=0.005^{*}$ & n.s. & $\mathrm{p}=0.002^{*}$ & \\
\hline
\end{tabular}

$P$, patients; C, controls; n.s., not significant.

Data are given as means; SD is given in parentheses.

Test items/subscales in which no statistical significances were found are not displayed.

* Significance between patients and control group at $p<0.05$.

†Significant gender-specific differences after Bonferroni-Holm correction.

\section{Distress and/or life events as triggers for B27-AU relapses}

Many patients $(57.9 \%)(\mathrm{n}=99, \mathrm{p}<0.001)$ had the impression that psychological factors had an influence in the sense of triggering B27-AU, and this occurred more often in women than in men ( $p=0.045$, figure 2$)$. Some patients $(34.5 \%$ ) could even state specific life events after which an attack had occurred (table 3 ).

Patients who had mentioned psychological stress with or without a life event ('distress' group) exhibited raised and depressive BDI sum scores (distress 10.1 \pm 7.9 , no distress 7.1 $\pm 5.4 ; p=0.008)$. The same finding was true when assessing only women $(p=0.042)$ or men $(p=0.056)$. These patients also reached higher scores for depressive coping on the FQCI (distress $11.4 \pm 4.3$, no distress $9.7 \pm 3.9 ; p<0.001$ ), independent of gender (women 11.6 \pm 3.7 , men 11.5 $\pm 4.8 ; \mathrm{p}=0.961$ ). On the SCI a difference was found for three of the 19 subscales (more resignation, more rumination, less playing down the disease; all $\mathrm{p}<0.001)$, together resulting in an elevated score of negative coping (distress 10.9 \pm 4.4 , no distress $8.3 \pm 3.6 ; \mathrm{p}<0.001$ ).

\section{DISCUSSION}

From the 1960s onwards a number of studies have discussed a connection between distress or depressive tendencies and uveitis (table 4). ${ }^{4-14}$

Nevertheless, these studies draw opposite conclusions. Various uveitis entities being grouped together, small sample sizes and

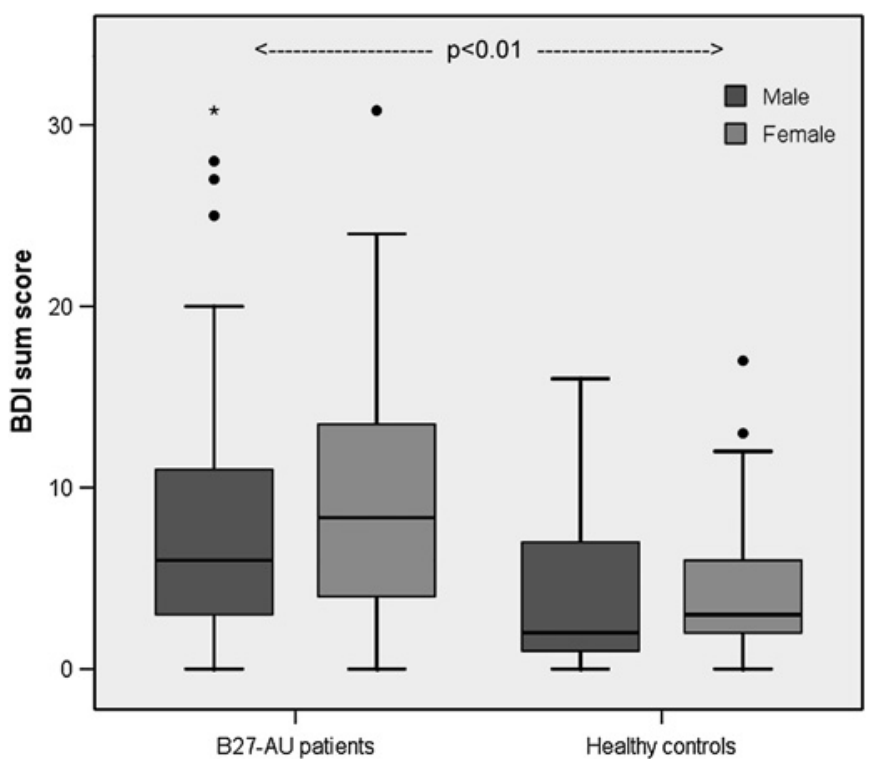

Figure 1 Results of the Beck Depression Inventory (BDI). The BDI sum score was slightly higher in female $(9.5 \pm 7.6)$ than in male B27-AU patients $(8.4 \pm 6.7, p=0.34)$. Both gender groups reached scores significantly higher than those of healthy controls (women $4.5 \pm 4.0$, $\mathrm{p}=0.004$; men $4.1 \pm 4.7, \mathrm{p}=0.002$ ). 


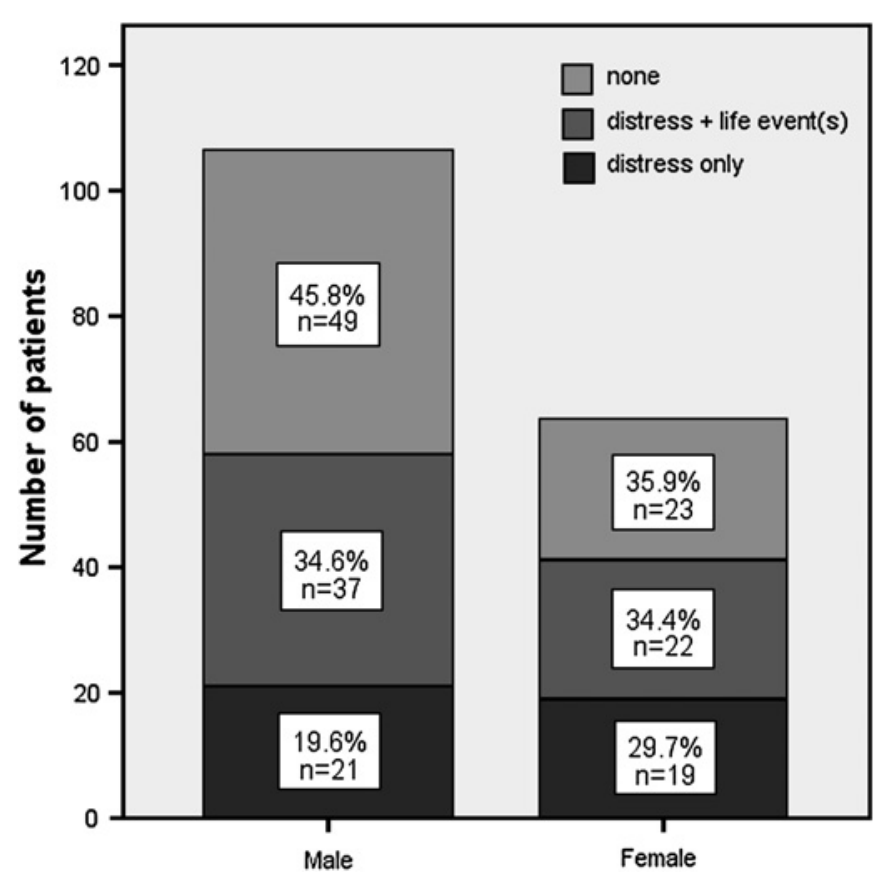

Figure 2 Numbers of HLA-B27-associated anterior uveitis (B27-AU) patients stating psychological distress with or without specific life events preceding an acute attack. Of 171 B27-AU patients, 99 (57.9\%) stated that they had felt psychological distress before acute relapses, $23.4 \%$ distress only, and $34.5 \%$ distress and specific life events. Women reported a connection more often than men $(p=0.045)$. Distributions within gender group are given in percentages (equal total).

the diversity of evaluation instruments (such as personal interviews versus questionnaires) may have led to these diverse results, which are difficult to compare. To overcome the limitations of previous studies we concentrated on a well-defined and homogenous uveitis entity and used only standardised questionnaires.

One aim of our study was to evaluate the patients' subjective impression of life events and psychological distress as a trigger for recurrences of $\mathrm{B} 27-\mathrm{AU}$. In our study population, $57.9 \%$ of the

Table 3 HLA-B27-associated anterior uveitis (B27-AU) patients' subjective estimations about psychological distress or life events as triggers for relapses

\begin{tabular}{llcc}
\hline & $\begin{array}{l}\text { Total patient } \\
\text { population }\end{array}$ & Women & Men \\
\hline Patients reporting of distress with or without & $57.9(99)$ & $64.1(41)^{*}$ & $54.2(58)$ \\
life event(s) before an B27-AU attack & & & \\
Patients stating distress only & $23.4(40)$ & $29.7(19)$ & $19.6(21)$ \\
Patients stating distress and specific life & $34.5(59)$ & $34.4(22)$ & $34.6(37)$ \\
events & & & \\
Life events (10 most often stated, in quantitative order) & & \\
Death in family & $18.1(31)$ & $21.9(14)$ & $15.9(17)$ \\
Separation & $15.2(26)$ & $14.1(9)$ & $15.9(17)$ \\
Common cold & $11.7(20)$ & $15.6(10)$ & $9.3(10)$ \\
Redundancy & $10.5(18)$ & $9.4(6)$ & $11.2(12)$ \\
Occupational change & $8.8(15)$ & $7.8(5)$ & $9.3(10)$ \\
Divorce & $8.8(15)$ & $10.9(7)$ & $7.5(8)$ \\
Diagnosis of an illness & $8.2(14)$ & $7.8(5)$ & $8.4(9)$ \\
Accident & $7.0(12)$ & $6.3(4)$ & $7.5(8)$ \\
Moving house & $6.4(11)$ & $9.4(6)$ & $4.7(5)$ \\
Birth of a child & $2.3(4)$ & $4.7(3)$ & $0.9(1)$ \\
\hline
\end{tabular}

Data are given as percentage relating to group (total of patients or gender); number of patients per gender group is given in parentheses.

${ }^{*}$ Significance at $\mathrm{p}<0.05$. patients reported life events and psychological distress as a potential triggers. Theories that distress might negatively influence the immune system via the neuro-endocrine system could be an explanation for a connection between distress and disease exacerbation, but have not been investigated closely enough to draw definite conclusions. ${ }^{21}$ Distress might play a role before an attack of B27-AU, but definitely plays a role in the time after. Future studies will have to investigate both topics, as too many interactions still remain unclear.

Furthermore, the presence of depressive symptoms, disease and stress-coping strategies were analysed using standardised and validated questionnaires. A special focus was set on analysing gender-specific differences. The male:female ratio of 1.7:1 is comparable to the findings of previous studies on B27AU patients. ${ }^{22}$ Test results indicating the presence of depressive moods were found in $31.6 \%$ of patients. These results support the data reported by Carrim et al, according to whom patients with acute AU experience an extraordinary burden in terms of their psychological well-being and general health (table 4). ${ }^{14}$ The patients investigated in that study achieved higher (ie, poorer) scores on the General Health Questionnaire than did controls. The General Health Questionnaire is a psychometric instrument measuring stress, social dysfunction and depression, and is therefore comparable with the BDI used in our study.

With regard to disease coping, we found specific behaviour patterns attributable to both sexes ('cognitive avoidance'), but also gender-specific ones. Franke et al, who studied psychosomatic aspects of 51 patients with various forms of uveitis in a pilot study, concluded that uveitis patients apply specific coping strategies, have a lower disease-specific quality of life and suffer from greater psychological distress (table 4). ${ }^{4}$ Our results thus provide another informative basis concerning B27AU patients.

Concerning gender-specific differences, women appear to suffer more from the psychological strain caused by B27-AU than men, which is demonstrated by specific behaviour patterns. In comparison with men, women exhibited a tendency towards depressive moods, with a strong bodily component as reflected in increased 'loss of libido'. A possible explanation for these results could be the knowledge that women are more sensitive to pain than men. In diseases associated with chronic pain women achieve higher scores concerning depression and dejection. ${ }^{23}$ Behavioural patterns during stressful situations also differed between genders (SCI), although findings in women were not as noticeable as in men. Male B27-AU patients exhibited predominantly negative coping strategies. This underlines the importance of differentiating between female and male patients in order to be able to offer a gender-tailored supportive approach.

As a probable limitation of the study the participation rate of $45 \%$ has to be discussed. According to various authors the response rates to postal surveys rarely exceed $50 \%{ }^{24} 25$, especially if no factors apply that are known to increase compliance (short questionnaires, complex follow-up procedures such as telephone contacts or re-sending the questionnaire or offering a monetary incentive). ${ }^{2426}$ None of the latter factors were used in our study, thus explaining the response rate achieved. Other problems in studies using questionnaires are those of social desirability bias and concealment of sensitive information. Besides the fact that these apply rather to personal or telephone interviews than to postal surveys, care was taken to compose an invitation letter without suggestive questions. We therefore believe that patients suffering from more versus fewer symptoms were addressed equally and our results are not biased in that way. 
Table 4 Previous studies on the psychopathology of uveitis

\begin{tabular}{|c|c|c|c|c|c|}
\hline Authors & Year & $\begin{array}{l}\text { Questionnaires } \\
\text { used (author) }\end{array}$ & $\begin{array}{l}\text { Number } \\
\text { of uveitis } \\
\text { patients }\end{array}$ & $\begin{array}{l}\text { Uveitis type, } \\
\text { number of patients }\end{array}$ & Results \\
\hline Schlaegel and Levitt ${ }^{5}$ & 1959 & $\begin{array}{l}\text { Minnesota Multiphasic } \\
\text { Personality Inventory }\end{array}$ & 49 & $\begin{array}{l}\mathrm{AU}, \mathrm{AU}+\mathrm{PU} \text {; granulomatous } \\
\text { versus non-granulomatous; } \\
\text { severity staging }\end{array}$ & $\begin{array}{l}\text { Significantly higher values of psychopathology in uveitis } \\
\text { patients; the location, type and severity of uveitis or sex } \\
\text { are not correlated with psycho-pathology. }\end{array}$ \\
\hline Erbaugh and Fajardo ${ }^{6}$ & 1962 & Personal interview & 71 & No details given & $\begin{array}{l}\text { Uveitis patients report more depressive episodes prior to } \\
\text { hospitalisation than controls. }\end{array}$ \\
\hline Heaton ${ }^{7}$ & 1964 & Personal interview & 224 & $\begin{array}{l}\text { AU }(n=157) \\
\text { PU }(n=20) \\
\text { Pan }(n=47)\end{array}$ & $\begin{array}{l}\text { Three potential triggers of the disease: (1) maladaptation to } \\
\text { the social environment may act as a predisposing factor } \\
\text { because } 21 \% \text { of patients mentioned interpersonal stress } \\
8 \text { weeks before uveitis; (2) influenza in } 6.2 \% \text {; } 3 \text { ) common } \\
\text { cold in } 3.6 \% \text {. }\end{array}$ \\
\hline $\operatorname{Sen}^{8}$ & 1971 & Personal interview & 48 & $\begin{array}{l}\text { AU }(n=36) \\
\text { PU }(n=5) \\
\text { Pan }(n=7)\end{array}$ & $\begin{array}{l}\text { Stress was reported as a factor influencing the } \\
\text { development or progression of uveitis by } 37.5 \% \text { of patients } \\
\text { (16.6\% reported stress in interpersonal relationships). }\end{array}$ \\
\hline Kumar $^{9}$ & 1981 & Modified Life Inventory Scale & 40 & Patients with controlled uveitis & Correlation between elevated stress scores and uveitis. \\
\hline Mulholland et $a l^{12}$ & 2000 & $\begin{array}{l}\text { Holmes and Rahe's Social } \\
\text { Readjustment Scale (Rahe), } \\
\text { Spielberger State-Trait Anxiety } \\
\text { Inventory (Spielberger) }\end{array}$ & 35 & Idiopathic RAAU $(\mathrm{n}=35)$ & Stress was not involved in triggering recurrences. \\
\hline Schiffman et al ${ }^{13}$ & 2001 & $\begin{array}{l}\text { SF-36 Health survey (Ware), } \\
\text { NEI VFO-25 (Mangione) }\end{array}$ & 76 & $\begin{array}{l}\text { AAU }(n=13) \\
\text { IU }(n=17) \\
\text { PU }(n=26) \\
\text { Pan }(n=20)\end{array}$ & $\begin{array}{l}\text { Scores significantly lower than those of the general US } \\
\text { population; the severity of uveitis is correlated with a drop } \\
\text { in scores. }\end{array}$ \\
\hline Franke et $a l^{4}$ & 2004 & $\begin{array}{l}\text { Schedule of Recent Experiences } \\
\text { (Holmes), Stress Coping Questionnaire } \\
\text { (Janke) Essen Coping Questionnaire } \\
\text { (Franke), Brief Symptom Inventory } \\
\text { (Derougatis), NEI VFO (Mangione) }\end{array}$ & 51 & Chronic uveitis $(n=51)$ & $\begin{array}{l}\text { Patients with uveitis: more numerous recent life events, } \\
\text { poorer coping strategies, greater psychological distress, } \\
\text { poorer quality of life. At follow-up patients with recurrence } \\
\text { of uveitis had poorer values than did those without } \\
\text { recurrence. }\end{array}$ \\
\hline
\end{tabular}

AAU, acute anterior uveitis; $A U$, anterior uveitis; IU, intermediate uveitis; NEI VFQ, National Eye Institute visual functioning questionnaire; PU, posterior uveitis; Pan, panuveitis; RAAU, recurrent acute anterior uveitis.

In conclusion, the results of our study indicate that patients with a history of B27-AU are at risk of suffering from depression and tend to use negative coping strategies. According to gender, patients are at risk of encountering specific and sustained psychological problems. A significant proportion of patients believed in psychological distress or life events as a potential trigger for recurrences. These results show that the management of uveitis patients should encompass not only standardised treatment strategies of the ocular disease itself, but also clear information about the relapsing nature of B27-AU, the potential role of distress or life events as triggers, and the disease's impact on psychological well-being. In addition, whenever possible a behaviour therapy focused on cognitive styles should be proposed, to support the patients' effort and success in dealing with the disease. Through identification of situations causing personal distress, patients can learn to either 'fight' or 'flight' in specific situations, depending upon individual coping patterns. To recognise the body's tendency towards highly charged states in distress situations, and to alter behaviour accordingly, can reduce the length of time a person suffers from distress, and reduce the body's continued need to produce epinephrine to cope with danger that does not really exist. Improving coping mechanisms in the therapeutic sense can involve meditation, Jacobson's progressive muscle relaxation, cognitive behavioural therapy and recognition of the body's inappropriate response to distress (eg, biofeedback).
Our findings confirm the need for an interdisciplinary and gender-tailored management of B27-AU that combines conventional treatment of uveitis with psychological counselling or guidance.

Funding This work has been partly supported by Kampf der Blindheit (Association for Prevention of Blindness) in Vienna. The sponsor was not involved in the design or conduct of the research project.

Competing interests None declared.

Patient consent Obtained.

Ethics approval This study was conducted with the approval of the Ethics Committee of the Medical University Vienna Borschkegasse 8b/6 A-1090 Vienna Austria and in accordance with the Declaration of Helsinki.

Provenance and peer review Not commissioned; externally peer reviewed.

\section{REFERENCES}

1. Power WJ, Rodriguez A, Pedroza-Seres $\mathbf{M}$, et al. Outcomes in anterior uveitis associated with the HLA-B27 haplotype. Ophthalmology 1998;105:1646-51.

2. Stoltz CM, Baime MJ, Yaffe K. Depression in the patient with rheumatologic disease. Rheum Dis Clin North Am 1999;25:687-702.

3. Barlow JH, Macey SJ, Struthers GR. Gender, depression, and ankylosing spondylitis. Arthritis Care Res 1993;6:45-51.

4. Franke GH, Schutte E, Heiligenhaus A. Rehabilitation - psychological aspects of uveitis. Psychother Psychosom Med Psychol 2005;55:65-71.

5. Schlaegel TF Jr, Levitt EE. Psychopathology in adults with uveitis. Am J Ophthalmol 1959;48:312-16.

6. Erbaugh JK, Fajardo RV. Emotional factors in uveitis: a pilot study. Surv Ophthalmol 1962; 7:199-204. 
7. Heaton JM. An ecologic approach to uveitis. Am J Ophthalmol 1964;57 122-8.

8. Sen DK. Endogenous uveitis in relation to stress - a clinical study. Eye Ear Nose Throat Mon 1971:50:108-10.

9. Kumar A, Nema HV, Thakur V. Stress and uveitis. Ann Ophthalmol 1981;13:1077-80

10. Secchi AG, Magni G, Tognon MS, et al. A psychosomatic approach to idiopathic recurrences of anterior uveitis. Am J Ophthalmol 1987;104:174-8.

11. Mayer H, Kraus-Mackiw E, Arocker-Mettinger E, et al. Psychosomatic aspects of uveitis in the context of working life. In: Nussenblatt RB, Whitcup SM, Caspi RR, et al, eds. Advances in ocular immunology. Amsterdam: Elsevier Science, 1994:349-52.

12. Mulholland B, Marks M, Lightman SL. Anterior uveitis and its relation to stress. Br J Ophthalmol 2000;84:1121-4.

13. Schiffman RM, Jacobsen G. Whitcup SM. Visual functioning and general health status in patients with uveitis. Arch Ophthalmol 2001;119:841-9.

14. Carrim ZI, Ahmed TY, Taguri AH. The relationship between stress and acute anterior uveitis. Acta Ophthalmol Scand 2006;84:795-8.

15. Mohr DC, Hart SL, Julian L, et al. Association between stressful life events and exacerbation in multiple sclerosis: a meta-analysis. BMJ 2004;328:731.

16. Karlidag R, Unal S, Evereklioglu C, et al. Stressful life events, anxiety, depression and coping mechanisms in patients with Behcet's disease. J Eur Acad Dermatol Venereol 2003:17:670-5.
17. Beck AT, Hautzinger M, Bailer M, et al. Beck depression inventory. Bern: Hans Hube Verlag, 1995

18. Muthny FA. Freiburger fragebogen zur krankheitsverarbeitung. Weinheim: Beltz Test $\mathrm{GmbH}, 1989$

19. Jahnke W, Erdmann G. Stressverarbeitungsfragebogen 120. Goettingen: Hogrefe Verlag, 1997

20. Holm S. A simple sequentially rejective multiple test procedure. Scand J Stat 1979;6:65-70

21. O'Connor GR. Factors related to the initiation and recurrence of uveitis. XL Edward Jackson memorial lecture. Am J Ophthalmol 1983;96:577-99.

22. Tay-Kearney ML, Schwam BL, Lowder C, et al. Clinical features and associated systemic diseases of HLA-B27 uveitis. Am J Ophthalmol 1996;121:47-56.

23. Schiesser AW, Katzenschlager S, Benetka G. Multimodel treatment of chronified, non malignant pain and its influence on pain behavior, social and psychological aspects. In: Hu F, ed, Pain research progress: migraine, fibromyalgia and related pain. Hauppauge, NY: Nova Science Publishers, 2008:151-74.

24. Nakash RA, Hutton JL, Jorstad-Stein EC, et al. Maximising response to postal questionnaires - a systematic review of randomised trials in health research. BMC Med Res Methodol 2006;6:5

25. Asch DA, Jedrziewski MK, Christakis NA. Response rates to mail surveys published in medical journals. J Clin Epidemiol 1997;50:1129-36.

26. Edwards $\mathbf{P}$, Roberts I, Clarke $\mathrm{M}$, et al. Methods to increase response rates to posta questionnaires. Cochrane Database Syst Rev 2007:(2):MR000008.

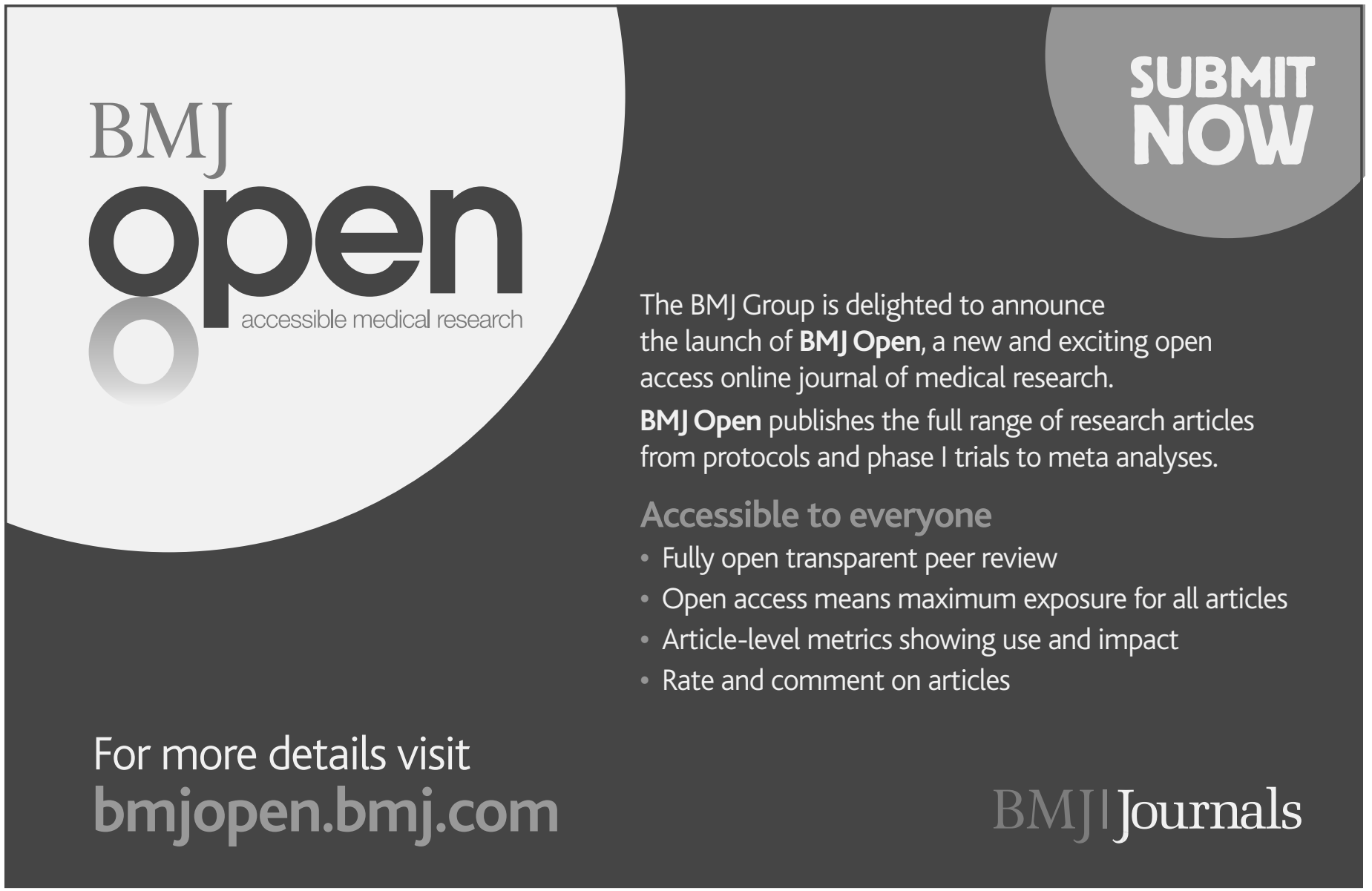

